\title{
Shaping the Health Policy Agenda: The Case of Safe Motherhood Policy in Vietnam
}

\author{
Bui Thi Thu $\mathrm{Ha}^{1 *}$, Tolib Mirzoev², Maitrayee Mukhopadhyay ${ }^{3}$
}

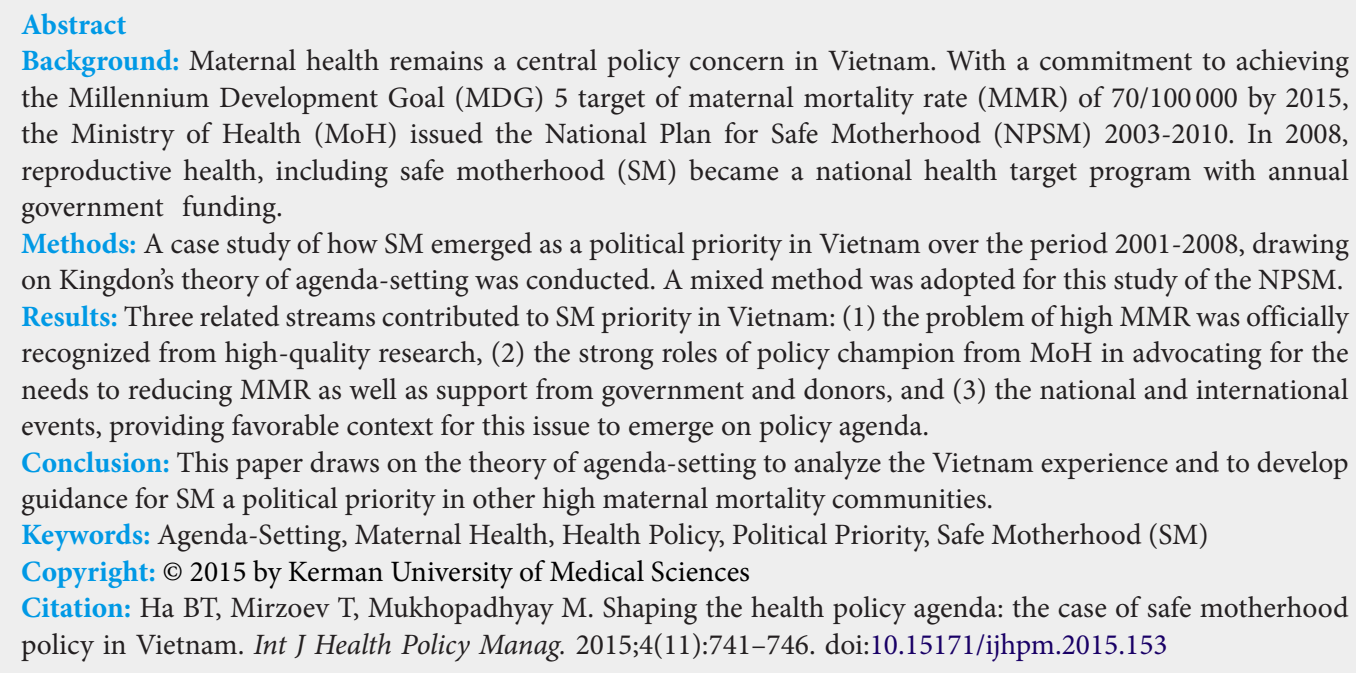

Background: Maternal health remains a central policy concern in Vietnam. With a commitment to achieving the Millennium Development Goal (MDG) 5 target of maternal mortality rate (MMR) of 70/100 000 by 2015, the Ministry of Health (MoH) issued the National Plan for Safe Motherhood (NPSM) 2003-2010. In 2008, reproductive health, including safe motherhood (SM) became a national health target program with annual government funding.

Methods: A case study of how SM emerged as a political priority in Vietnam over the period 2001-2008, drawing on Kingdon's theory of agenda-setting was conducted. A mixed method was adopted for this study of the NPSM. Results: Three related streams contributed to SM priority in Vietnam: (1) the problem of high MMR was officially recognized from high-quality research, (2) the strong roles of policy champion from $\mathrm{MoH}$ in advocating for the needs to reducing MMR as well as support from government and donors, and (3) the national and international events, providing favorable context for this issue to emerge on policy agenda.

Conclusion: This paper draws on the theory of agenda-setting to analyze the Vietnam experience and to develop guidance for SM a political priority in other high maternal mortality communities.

Keywords: Agenda-Setting, Maternal Health, Health Policy, Political Priority, Safe Motherhood (SM)

Copyright: $\odot 2015$ by Kerman University of Medical Sciences

Citation: Ha BT, Mirzoev T, Mukhopadhyay M. Shaping the health policy agenda: the case of safe motherhood policy in Vietnam. Int J Health Policy Manag. 2015;4(11):741-746. doi:10.15171/ijhpm.2015.153

\section{Article History:}

Received: 14 March 2015 Accepted: 13 August 2015 ePublished: 16 August 2015

\section{Key Messages}

Implications for policy makers

- The available evidence will help to justify the severity of health problem

- The perceived quality of evidence is not always meet all criteria (credibility, generalisability, reliability, objectivity, and rootedness)

- Advocacy skills are important for getting attention from policy-makers to health problem.

\section{Implications for public}

High maternal mortality remains a central policy concern in Vietnam. With great efforts from Ministry of Health (MoH) and other international development partners, safe motherhood (SM) policy aiming to reduce maternal mortality, was received attention from government and became a national health target program with annual government funding since 2008.

\section{Background}

Maternal health is a central policy concern in Vietnam, as reflected in the National Strategy on Reproductive Health 2001-2010. ${ }^{1}$ In 2001, the national maternal mortality rate (MMR) was 165/100 000 live births and much higher in remote and mountainous regions $411 / 1000000^{2,3}$ With a commitment to achieve the MDG 5 target to reach MMR of 58.3/100 000 by 2015 , the Ministry of Health $(\mathrm{MoH})$ issued the National Plan for Safe Motherhood (NPSM) 2003-2010, which aimed to ensure safe motherhood (SM) services available to every woman and newborn. ${ }^{4}$ In 2012, MoH renewed the NPSM and Newborn Care 2011-2015 with particular attention to difficult regions and vulnerable groups. ${ }^{5}$ In the last 15 years, SM still high profile in the policy agenda in Vietnam. This paper explores how the political priority for SM emerged and was sustained during period 2001-2008 in Vietnam. The results of this study should be of interest to policy-makers, researchers and other policy actors interested in improving their understanding of processes for initiating health policies in Vietnam and similar contexts.

We use the Kingdon's theory of agenda-setting as a framework for analysis. ${ }^{6}$ Agenda-setting is the stage of the policy process during which the issues rises to prominence. It is the first stage in policy processes and precedes the others: development and implementation. ${ }^{7}$ Political priority refers to the degree to which political leaders consider an issue to be worthy of sustained attention and back this up with provision of financial, human, and technical resources. ${ }^{8}$ According to Kingdon, an issue emerges on national agendas when three streams - problems, policies, and politics - flow together and 
eventually converge. ${ }^{6}$ The problem stream refers to broad issues faced by societies. The policy stream refers to the proposed interventions to address the problems. The politics stream refers to global or national political events that are associated with the problem. According to Kingdon, convergence of these 3 streams can create favourable environment to open a window of opportunity to place a particular issue on a policy agenda.

\section{Methods}

This paper is developed from a larger HEPVIC project - "Health Policy Processes in Vietnam, India, and China" - a multi-partner 3-year research which explored maternal health policy processes in the 2 Asian countries., ${ }^{9,10}$ The research analyzed all stages of policy processes: policy agenda-setting, development and implementation. ${ }^{9}$ In Vietnam, the NPSM 2003-2010 was selected to study the policy on skilled birth attendance (SBA). ${ }^{10}$

The data collection was undertaken between December 2006 and July 2008, using in-depth interviews and focus group discussions with key policy actors and document review, as we set out next.

Purposive sampling was used to develop the initial list of respondents for interviews on the basis of their roles in health policy processes, which was followed by snowballing technique to identify further respondents. There were 13 indepth interviews and 1 focus group discussion with policymakers, managers/planners, researchers, civil societies, international development partners/donors and politicians. All interviews and a focus group discussion were conducted using a semi-structured guide which included questions exploring respondents' understanding of policy processes, their role in these processes as well as their perceptions of strengths and weaknesses of these processes. Following informed consent from all respondents, all interviews and focus group discussion were audio-recorded and transcribed for analysis.

A total of 37 documents related to SM were reviewed. ${ }^{10}$ These documents included government policies (5), minutes of meeting (1), annual reports (11), newspapers (4), websites (2), research reports (12) and guidelines by government (2). These documents were identified through the discussions with key informants and searching the $\mathrm{MoH}$, government and programme websites.

The research team at the Hanoi School of Public Health, Hà Nội, Vietnam supported by European partners, carried out the data collection and analysis. The data was analysed using a framework approach ${ }^{11}$ comprising 5 stages (familiarisation with the data, identifying thematic framework, indexing, charting, and mapping and interpretation), with the support of qualitative data analysis software (NVivo 7.0). As mentioned earlier, the analysis of data reported in this paper was guided by Kingdon's multiple streams theory of agenda-setting ${ }^{12}-$ the only theory we found which helped us to understand the complexity of agenda-setting processes. The multiple streams theory helped to categorise the data for analysis (ie, provided thematic framework and informed indexing and charting of data) and structure reporting of the results. Draft findings were discussed with, and validated by, researcher partners and other stakeholders.
Results

Health policy processes are generally government-led, and there is increasing recognition of the involvement of actors outside both the government sector and the health system. ${ }^{13-15}$ In Vietnam, since 2008, all policies have to follow the Law on the promulgation of legal documents, ${ }^{16}$ which stipulated the following stages for public policies: policy proposal, development, implementation, and evaluation. The main factors affecting the policy processes which emerged from our analysis and reported elsewhere are: nature of the policy issue, involvement of different actors and national and international context. ${ }^{10}$ In recent years, under the Law on promulgation of legal document, the health policy processes in Vietnam have become more consultative, involving more actors, and taking into account people's values and beliefs. ${ }^{15,16}$ Figure 1 summarises the key stages of NPSM policy processes in Vietnam.

The NPSM policy processes were: agenda-setting, development and nationwide implementation. ${ }^{10}$ The agenda-setting was evident during the period 2000-2002 and the development phase was during 2002. The first phase of implementation occurred during 2003-2006 in 6 districts within 3 provinces and the second phase (2006-2010) expanded to 14 high-MMR provinces. The Royal Netherlands Embassy (RNE) provided the funding for NPSM policy processes, both development and implementation.

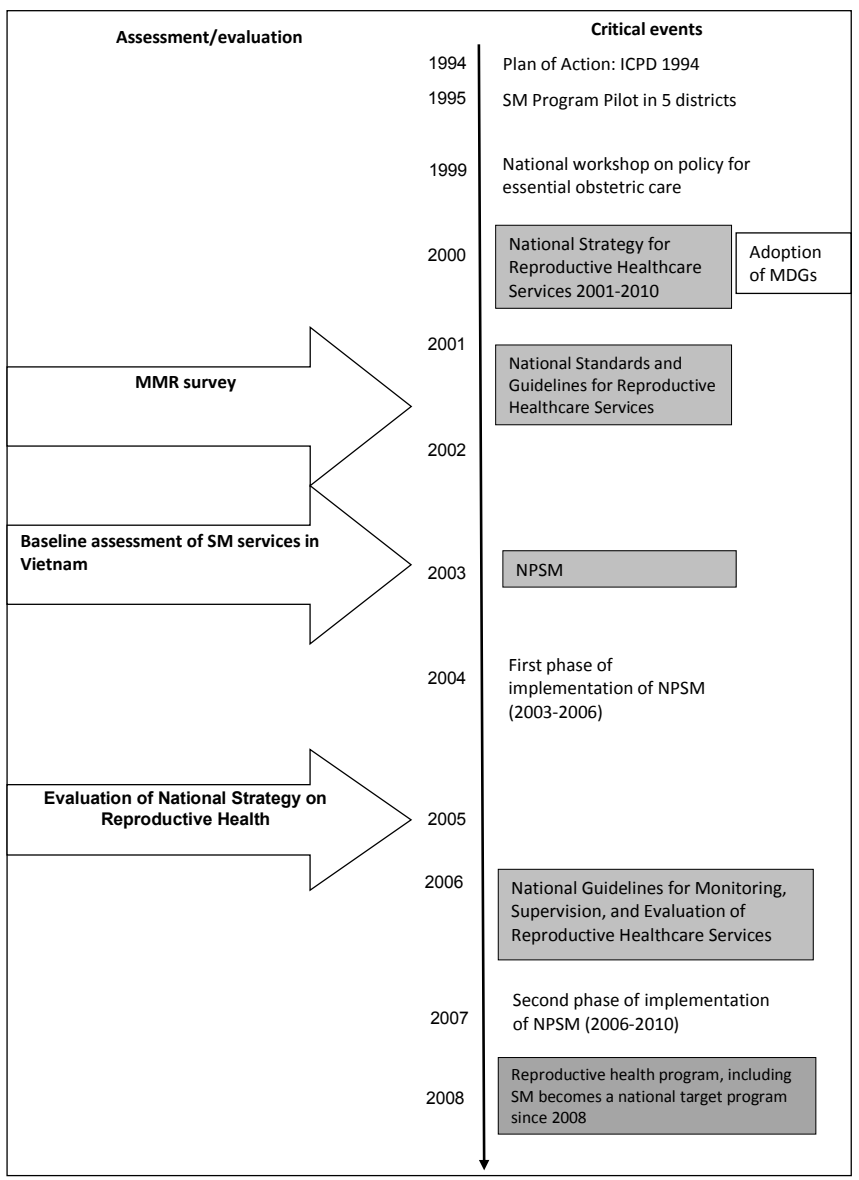

Figure 1. Timeline of Critical Steps Within SM Policy Processes in Vietnam. Abbreviations: SM, safe motherhood; ICPD, International Conference on Population and Development; MDG, Millennium Development Goal; MMR, maternal mortality rate; NPSM, National Plan for Safe Motherhood. 
Different factors appear to have contributed to the agendasetting of NPSM. These correspond to the Kingdon's three streams, as we set out next:

- Problem stream: maternal mortality survey

- Policy stream: support by a policy champion, donors, and government

- Politics stream: national and international events (International Conference on Population and Development [ICPD] and MDG)

\section{Problem Stream: Maternal Mortality Survey}

The main problem which informed the development of NPSM was high maternal mortality in the country. A maternal mortality survey was commissioned in 2001 by the $\mathrm{MoH}$ Reproductive Health (RH) Department, with financial support from World Health Organization (WHO) and advisory support from the Minister of Health. ${ }^{2,3}$ The WHO also provided technical assistance in the design, supervision and validation of results. The study revealed the high MMR at $165 / 100000$ live births, and up to $411 / 100000$ in the remote and mountainous regions, which was much higher than data from the official health statistic yearbook (95/100000). The results were presented by a policy-maker from the $\mathrm{RH}$ department at an internal $\mathrm{MoH}$ meeting, but results were contested by some other key $\mathrm{MoH}$ officials because, according to the respondents, this implied the failure of the $\mathrm{MoH}$ efforts to tackle this issue:

"They do not want to accept this because of their reported progress up to now. The reported MMR was much lower (95/100000) compared to the MMR study results.... This will lead to questioning the $\mathrm{MoH}$ contribution to reducing $M M R$ " (Policy-maker).

Nevertheless, the results were disseminated at another national workshop with presence of international agencies, government officials, implementers, researchers and other stakeholders, and published later in a WHO monograph in $2005 .^{3}$ Although these results were never officially recognized by the $\mathrm{MoH}$ in an official yearbook summarizing health statistics, most key stakeholders, including the $\mathrm{MoH}$ officials, regarded this as the most important study that brought attention of policy-makers to the issue of SM in Vietnam and provided the rationale for development of NPSM ${ }^{4}$ :

"This [survey] is the important data to alarm people about high MMR in Vietnam and the needs for solutions" (Researcher).

Policy Stream: Support by a Policy Champion, Government, and Donors

The NPSM proposed different strategies for improved service delivery on SM by 2010 which related to availability, accessibility and quality of obstetric and neonatal care at commune health centers and district hospitals. In remote and mountainous regions, whereas the skilled birth attendants were not available, NPSM proposed to train traditional birth attendants with specific skills to help them attend safe clean deliveries.

"Ethnic people are living in the ethnic region with ethnic people, and need trained people to diagnose the condition of pregnant women, who can delivery at home and who need to transfer to higher level in case of complication. Time for training is 9 months" (Health Manager).
One key person from the $\mathrm{MoH}$ Reproductive Health department played the roles of both policy developer and implementer. This person had several meetings and discussions with donors and politicians to advocate for the need for reducing MMR in Vietnam, particularly in remote and mountainous regions.

This person requested the WHO to provide funds for the MMR survey and later became an advocate of the study results. According to the respondents, the person believed the MMR results were reliable because of the high technical competence of the WHO.

"The study was designed and supervised by WHO and results were reliable and valid" (Policy-maker).

Despite the resistance from other $\mathrm{MoH}$ officials in acknowledging the results which showed the high MMR in Vietnam, the person continuously advocated for, and eventually obtained, support from the Minister of Health for developing the SM policy in Vietnam.

"I convinced the Minister of Health to accept the high MMR results and approve the development of SM policy" (Policymaker).

Different respondents reflected that the champion's commitment to reduce high MMR in these regions appears to follow on from their 40 years working experiences as an obstetrician, during which they witnessed many maternal deaths especially in the mountainous region.

"[the person] was asked to conduct the program on SM, because this is important and ... [the person] was a OB/GYN" (Manager).

This resulted in getting the approval from Minister of Health to develop NPSM 2003-2010 and illustrated in Decision 5792/2003/QD-BYT on approval of NPSM in Vietnam 20032010. The strong championship by a policy champion was acknowledged by a different stakeholder as being pivotal in agenda-setting for this policy:

"Without the contribution of this policy-maker..., no SM program would have been done in Vietnam" (Development partner).

The $\mathrm{MoH}$ then contacted the Government about the need to adopt the NPSM as the national target program. This was in recognition of the importance of reducing MMR to meet the MDG 5 target. During 2000-2007 most funding for reproductive health came from the donors, such as United Nations Population Fund (UNFPA) and United Nations Children's Fund (UNICEF). However, since 2008 the RH program was given annual state funding of approximately $\$ 2$ million. ${ }^{17}$

The policy champion relied on their reputation of having extensive experience in obstetrics and gynecology, and emphasized maternal mortality to convince the RNE to support the development of a SM policy in Vietnam. The RNE has been actively supporting the health sector in Vietnam since 2000 through a sector-wide approach. Reduction of MMR and reaching MDG goals were in line with RNE mandates in their priorities for supporting the health sector in Vietnam. Therefore, the RNE decided to support the $\mathrm{MoH}$ in developing NPSM by providing a grant to the MoH in 2003.

"The RNE has the mandate to support the health sector and SM is one of priority of $\mathrm{MoH}$ which will help to achieve the MDG goals" (Development partner). 
The RNE provided financial and technical support to development and implementation of the first and second phase of NPSM during 2002-2012. The RNE participated in several meetings with $\mathrm{RH}$ department leaders, the $\mathrm{MoH}$ and the National Technical Advisory Committee on policy development. The RNE also advocated that addressing SM should also include other social sectors and civil society organizations (CSOs).

In relation to involvement of CSOs, the Vietnam Women Union was invited in the agenda-setting because they also advocated for the needs of reducing MMR in the country. However, they were not invited further in development phase, due to a perception of their lack of technical expertise by policy-makers:

"Safe motherhood is medical issues, and women union does not have expertise on this aspect" (Policy-maker).

This is an interesting finding, suggesting the perceived low value of CSO involvement, although the development of the new NPSM more recently in 2010 benefited from a wider involvement of CSOs.

Politics Stream: National and International Events

Since the International Safe Motherhood Conference in Nairobi (1987), there has been a significant change in world's opinion on SM. Several international events were organized, for example: the ICPD Programme of Action (1994) and Safe Motherhood Initiative - 10th year State-of-the-Art meeting in Colombo, Sri Lanka (1997).

According to the documents, the ICPD 1994 led to changing the attitudes of policy-makers and health managers, and National Strategy for Reproductive Health 2001-2010 was developed with ICPD comprehensive reproductive health vision. ${ }^{1}$ The evaluation of strategy implementation in 2010 has shown that the SM was a priority area for Vietnam's $\mathrm{MoH}$ and most programs and projects implemented during this period were related to SM. ${ }^{18}$

In 2000, the United Nation (UN) approved the MDGs, which included a goal of a 75\% reduction in MMR. The Millennium Summit situated the MMR in a broader context of poverty reduction and development efforts. SM, therefore, became a central component for the achievement of women's health and rights. Vietnam was a signatory of the Millennium Declaration. The $\mathrm{MoH}$ was assigned as being in charge of activities to achieve MDG 5 and promulgated different strategies to reduce MMR. These included the National Population Strategy 2001-2010, National Strategy on Reproductive Healthcare Services 2001-2010 and the National Standards and Guidelines on Reproductive Healthcare Services.

Emergency obstetric care and SBA was internationally recognized as important strategy for ensuring safe delivery. ${ }^{19,20}$ In Vietnam, the first national workshop on policy for essential emergency obstetric care was organized in 1999. In this workshop, the $\mathrm{MoH}$ policy-makers emphasized the need to upgrade staff knowledge and expertise. The indicator: "deliveries with assistance of health workers" was renamed as "deliveries with assistance of trained health workers." The concept of "trained health worker" was interpreted as "skilled birth attendant"; specific examples included nurses, midwives and assistant doctors trained to be able to handle a 'clean and safe delivery', meaning avoiding complications and deaths. Only in 2014, the core skills of SBA that recommended by WHO was approved by $\mathrm{MoH}$ in Vietnam. ${ }^{21}$

\section{The Confluence of Streams}

All 3 streams of Kingdon's agenda-setting (problem, policy, and politics) were evident in the emergence of SM as a policy priority in Vietnam. In 2003, these streams converged which appear to have created a window of opportunity to get this issue onto the policy agenda. At that time, the results of survey showing high MMR were recognized by the key policy actors as credible and the problem was pinpointed. At about the same time, as shown earlier, the government and donors agreed on policy development and intervention plan thus giving coherence to the policy stream. In relation to the political stream, the MDGs in particular contributed to a favorable environment for the development of NPSM.

"MDG is the most important goal that MoH should be targeted to in terms of reducing MMR in the country" (Policy-maker).

This confluence of 3 streams led national policy-makers to give sustained attention to SM issues, authorized a national target program and resulted in the continuous allocation of a state budget for the program since 2008 until now.

\section{Discussion}

SM became one of Vietnam's foremost health priorities, and between 1990 and 2003, the maternal mortality was declined from 230 to $165 / 100000$ live births. This problem was clearly perceived as the responsibility of the health sector and was coordinated by the MoH RH department. The agenda-setting of NPSM in Vietnam could be seen as quite linear process, and emerged almost simultaneously with confluence of 3 streams and having approval of NPSM. ${ }^{10}$ Our findings suggest that different factors influenced the speed of agenda-setting for NPSM in Vietnam. These are existence of clear policy option, cohesion between policy actors, and existence of credible indicators, as we set out next.

\section{Policy Community Cohesion}

Policy communities play important roles in shaping national priorities, including SM. ${ }^{22}$ A similar finding was reported in this case. The policy community for the NPSM policy included the $\mathrm{MoH}$ policy-makers, obstetrician, Vietnam Women Union, CSOs and development partners (RNE) and other implementers at local level. All held commitment to reducing maternal deaths, as shown earlier. Most actors at $\mathrm{MoH}$ had medical background and therefore, the issue of SM was considered as a technical one. This explains why the Women Union was not invited, as being perceived by the $\mathrm{MoH}$ as having lack of technical knowledge. This perception contrasts with findings from other studies of SM policy development such as in Nigeria or India, where the CSOs were seen differently for example in White Ribbon in India. ${ }^{23}$ In our study, the roles of policy champion are prominent in agenda-setting, a finding which is similar to other contexts. In India, the Prime Minister played significant role in shifting the SM from a condition into a problem. In Nigeria, Honduras, Indonesia, and Vietnam, the $\mathrm{MoH}$ officials played important roles in developing SM policies. ${ }^{7,23,24}$ It can be seen that the policy champion is typically a powerful individual, located 
at national level and having good connections with different stakeholders including donors. The person can disseminate, advocate and mobilize support and resources. Furthermore, the person can actively facilitate placing problems onto the policy agenda, instead of waiting for windows of opportunity to emerge. However, in Vietnam, it appears that the policy issue and global political agenda have more influence than power from individual policy actors. ${ }^{10}$

The development partners can often be important in policy processes. We found that the active participation of RNE had a special effect on the SM agenda. They provided funding to develop, and later implement, the SM policy, which contributed to acceptance of SM as a priority by the government. Similarly, in other countries powerful external partners provided crucial financial and technical support in policy processes: for example, UNICEF, and WB in India; DFID Path in Nigeria; USAID, WB, the Netherlands Embassy in Honduras. ${ }^{7,23}$ Although there is no direct evidence from our study, the long history of RNE support to the health sector may have also contributed to their credibility and power in the health sector, as compared to other bilateral and multilateral agencies.

\section{Clear Policy Option}

The international norm that advocated for SM such as obstetric care and SBA provided a clear intervention for reducing MMR in the country. ${ }^{22}$ The policy option, which was deliveries with assistance of SBA, was non-controversial. However, some modification was introduced for the Vietnamese context: institutional delivery in mainland areas and home delivery by trained health workers in mountainous areas.

We found that existence of a global norm and a clear policy option were an influential force in the country's decisions to address the causes of maternal mortality. This made it easier to bring the topic to the policy table, increased the likelihood of obtaining support from politicians, policy-makers and development partners, and consequently reduced the time for agenda-setting ${ }^{10}$; a finding which is similar to the results of studies found in India and Indonesia. ${ }^{8,24}$

\section{Credible Indicators}

It is important to have sources of credible evidence to highlight the issues such as high MMR to indicate the severity of problem to the policy-makers. ${ }^{22}$ These sources were clearly identified in other countries such as National Family Health Survey in India, ${ }^{8}$ maternal mortality survey in Honduras ${ }^{7}$ and IDHS survey in Indonesia. ${ }^{24} \mathrm{~A}$ similar phenomenon was reported in our study, with maternal mortality survey Vietnam $^{2}$ considered as trustworthy by many policy-makers in making the decision to develop the NPSM. On the other hand, when the reliable data was not available, policy-makers may ignore the issue because they are unaware of problem or unconvinced due to absence of evidence that any problem exists.

Policy Implications for Future Agenda-Setting Initiatives After 10 years, the SM policy remains high on the health policy agenda in Vietnam. The new National Plan of SM was developed for 2011-2020 with a focus to reduce the disparity in
MMR rates between the regions. The SM program continues receiving the annual government funding.

Three lessons can be shared from our study to inform future efforts on generation of political priority for the public health agenda. First, credible evidence to catalyze action and the strategic deployment of data are important to identify the problem and highlight it to key policy actors.

Second, powerful policy champions are crucial in driving the policy process and convincing donors and other policymakers on the needs of developing a particular policy. The $\mathrm{MoH}$ officials can often lack effective advocacy skills, which appear essential for such champions.

Third, the power of relevant national and international events, informing simple and effective policy proposals cannot be underestimated. In our case, the SM proposal focused on WHO-recommended effective interventions. Such proposals can easily get attention by the policy-makers, compared with more complex ideas which can often have less clearlydefined gains.

In seeking to draw principles from our study to other settings, there is a need for caution. Although not evident in our data, there are some unique aspects of the political context of Vietnam that shaped SM issues, which can also be regarded as preconditions for the agenda-setting in other contexts, in addition to the three streams discussed earlier. Vietnam has a relatively well-functioning health system and good health indicators, compared with countries at similar income levels. The health system is well-developed, for example reflected in nationwide coverage of essential healthcare services. The government is demonstrating commitment to providing quality healthcare for its people, especially to reduce MMR. The wider reforms allowed the government to have better economic growth with potential further benefits to the society, such as increased resources to achieve better health outcomes.

\section{Conclusion}

The generation of priority for SM in Vietnam required combination of three streams: $(a)$ development of reliable data to mark the severity of problem, $(b)$ the persistence and commitment of policy champions leading to support from other policy actors such as international donors and government, and $(c)$ the organization of attention-generating international and national events. The additional unique aspects of the context of Vietnam, such as existence of health reforms, can also be seen as prerequisites for the policy agenda-setting in other settings. Three policy implications for future agenda-setting initiatives are proposed, including the generation of credible evidence, existence of powerful champions and building on related national and international events.

\begin{abstract}
Ethical issues
The ethical approval for this study was obtained from the Institutional Review
\end{abstract} Board of Hanoi School of Public Health, Hà Nội, Vietnam.

Competing interests

Authors declare that they have no competing interests.

\section{Authors' contributions}

BTTH participated in design of study, carried out the study, drafted the manuscript. TM and MM participated in design of study, reviewed and edited 
the manuscript. All authors read and approved the final manuscript.

\section{Authors' affiliations}

${ }^{1}$ Hanoi School of Public Health, Hà Nội, Vietnam. ${ }^{2}$ Nuffield Centre for International Health and Development, University of Leeds, Leeds, UK. ${ }^{3}$ Royal Tropical Institute, Amsterdam, The Netherlands.

\section{References}

1. Ministry of Health $(\mathrm{MoH})$. National Strategy on Reproductive Health Care 2001-2010. Resolution No 136/QD-TTg by Priminister at November 28, 2000; 2000.

2. Ministry of Health $(\mathrm{MoH})$. Maternal Mortality in Vietnam 20002001: an in-depth analysis of causes and determinant. $\mathrm{MoH}$; 2002.

3. World Health Organization (WHO). Maternal Mortality in Vietnam 2000-2001: An In-depth Analysis of Causes and Determinants. Geneva: WHO; 2005.

4. Ministry of Health $(\mathrm{MoH})$. Decision by Minister of Health on the Approval of National Plan of Safe Motherhood in Vietnam 2003 - 2010. 5792/2003/QD-BYT, 2003.

5. Ministry of Health $(\mathrm{MoH})$. National Plan for Reproductive Health, focusing on Safe Motherhood and Newborn Care 2011-2015. 2718/QD-BYT, 2012.

6. Kingdon J. Agendas, Alternatives and Public Policies. 2nd ed. New York: Longman; 1984.

7. Shiffman J, Stanton C, Salazar P. The emergence of political priority for safe motherhood in Honduras. Health Policy Plan. 2004;19(6):380-390. doi:10.1093/heapol/czh053

8. Shiffman J, Ved R. The state of political priority for safe motherhood in India. BJOG. 2007;114:785-790. doi:10.1111/ j.1471-0528.2007.01374.x

9. Green A, Gerein N, Mirzoev T, et al. Health policy processes in maternal health: a comparison of Vietnam, India and China. Health Policy. 2011;100(2-3):167-173. doi:10.1016/j. healthpol.2010.11.016

10. Ha B, Green A, Gerein N, Danielsen K. Health policy processes in Vietnam: a comparison of three maternal health case studies. Health Policy. 2010;98(2-3):178-185. doi:10.1016/j. healthpol.2010.06.015
11. Ritchie J, Spencer L. Qualitative data analysis for applied policy research. In: Bryman A, Burgess R, eds. Analyzing Qualitative Data. New York: Routledge; 1994.

12. Kingdon JW. Agendas, Alternatives, and Public Policies. New York: Harper Collins; 1995.

13. Hajer M, Wagenaar H. Deliberative policy analysis. Cambrigde: Cambrigge University Press; 2003.

14. Ministry of Health (MoH). Vietnam Health Report 2006. $\mathrm{MoH}$; 2007.

15. Ministry of Health $(\mathrm{MoH})$, Health Partnership Group. Joint Annual Health Review 2010. Vietnam's Health System on the Threshold of the Five-year Plan 2011-2015. Hanoi, Vietnam: MoH; 2010.

16. National Assembly. Law on the promulgation of legal documents of the National Assembly (12th Legislature). N17/2008/QH12 on June 03, 2008.

17. Ha B, Huong N, Dung P. Assessment of implementation of national reproductive health care strategy 2000-2010: Hanoi School of Public Health; 2009.

18. Hanoi School of Public Health. Country report on health policymaking in Vietnam, its determinants and their inter-relationshipsHEPVIC project; 2009.

19. Campbell OM, Graham W. Strategies for reducing maternal mortality: getting on with what works. Lancet. 2006;368:12841299. doi:10.1016/s0140-6736(06)69381-1

20. World Health Organization (WHO). Making pregnancy safer: the critical role of the skilled attendant. A joint statement by WHO, ICM and FIGO. Geneva: WHO; 2004.

21. Ministry of Health $(\mathrm{MoH})$. Decision on approval of training manual on core competencies of skilled birth attendants. 3982/ QD-BYT, 2014.

22. Shiffman J. Generating Political Priority for Maternal Mortality Reduction in 5 Developing Countries. Am J Public Health. 2007;97:796-803. doi:10.2105/ajph.2006.095455

23. Shiffman J, Okonofua $F$. The state of political priority for safe motherhood in Nigeria. BJOG. 2007;114:127-133. doi:10.1111/ j.1471-0528.2006.01184.x

24. Shiffman J. Generating political will for safe motherhood in IndonesiaS. Soc Sci Med. 2003;56:1197-1207. doi:10.1016/ s0277-9536(02)00119-3 